\title{
Erratum to: Household preferences for reducing greenhouse gas emissions in four European high-income countries: Does health information matter? A mixed-methods study protocol
}

Alina Herrmann ${ }^{1 *}$, Helen Fischer ${ }^{1,2}$, Dorothee Amelung ${ }^{1,2}$, Dorian Litvine ${ }^{3}$, Carlo Aall ${ }^{4}$, Camilla Andersson ${ }^{5}$, Marta Baltruszewicz ${ }^{4}$, Carine Barbier ${ }^{6}$, Sébastien Bruyère ${ }^{3}$, Françoise Bénévise ${ }^{3}$, Ghislain Dubois ${ }^{3}$, Valérie R. Louis ${ }^{1}$, Maria Nilsson ${ }^{5}$, Karen Richardsen Moberg ${ }^{4}$, Bore Sköld ${ }^{5}$ and Rainer Sauerborn ${ }^{1}$

\section{Erratum}

After publication of the article [1], it has been brought to our attention that the titles of Figs. 4 and 5 have been transposed. Figure 4 should be titled "Overview on HOPE Study Protocol" and Fig. 5 should be titled "Tasks in the three rounds of the on-site simulation in Interaction 2". The original article has been revised to reflect this.

\footnotetext{
Author details

${ }^{1}$ Institute of Public Health, Heidelberg University Hospital, Im Neuenheimer Feld 130.3, 69120 Heidelberg, Germany. ${ }^{2}$ Institute of Psychology, Heidelberg University, Heidelberg, Germany. ${ }^{3}$ 3TEC-Conseil, Marseille, France.

${ }^{4}$ Vestlandforsking, Sogndal, Norway. ${ }^{5}$ Department of Public Health and Clinical Medicine, Epidemiology and Global Health, Umeå University, Umeå, Sweden. ${ }^{6}$ Centre International de Recherche sur l'Environnement et le Developpement (CIRED), Nogent, France.
}

Received: 9 August 2017 Accepted: 11 August 2017

Published online: 29 August 2017

\section{Reference}

1. Herrmann A, Fischer H, Amelung D, Litvine D, Aall C, Andersson C, et al. Household preferences for reducing greenhouse gas emissions in four European high-income countries: Does health information matter? A mixed-methods study protocol BMC Public Health. 2017;18:1. doi:10.1186/s12889-017-4604-1.

\footnotetext{
* Correspondence: alina.herrmann@uni-heidelberg.de

${ }^{1}$ Institute of Public Health, Heidelberg University Hospital, Im Neuenheimer Feld 130.3, 69120 Heidelberg, Germany

Full list of author information is available at the end of the article
} 